\title{
Model Aktivitas Online Learning di Perguruan Tinggi pada Masa Pandemi COVID-19
}

\author{
Handrie Noprisson \\ Fakultas Ilmu Komputer, Universitas Mercu Buana, Indonesia \\ handrie.noprisson@mercubuana.ac.id
}

\begin{tabular}{l} 
Article Info \\
\hline Article history: \\
Received, 02-04-2021 \\
Revised, 02-06-2021 \\
Accepted, 14-06-2021 \\
\hline Kata Kunci: \\
systematic review \\
online learning \\
COVID-19 \\
model online learning \\
\hline \hline
\end{tabular}

\section{Keywords:}

systematic review online learning

COVID-19

model online learning

\begin{abstract}
ABSTRAK
Penelitian ini bertujuan untuk mengusulkan model konseptual aktivitas online learning di perguruan tinggi pada masa pandemi COVID-19. Model ini dibangun dengan menganalisis kondisi pengguna, proses dan teknologi yang digunakan pembelajaran online selama pandemi COVID-19. Penelitian ini terdiri dari tahapan pengumpulan data, identifikasi aktvitas online learning selama pandemi COVID-19, pemetaan aktivitas terhadap dimensi model dan perancangan model konseptual online learning selama pandemi COVID-19. Data penelitian didapatkan dari database penelitian seperti PubMed, ProQuest, Science Direct, Google Scholar, IEEE Xplore dan Wiley Online Library. Hasil dari penelitian adalah model konseptual aktivitas online learning dengan komponen model terdiri dari people (mahasiswa, pengajar dan staf akademik), process (learning/cognitive process, pengaturan diri dalam belajar/student self regulation, interaksi manusia), technology (learning management system, interaction support tools, komputer/smartphone dan internet).
\end{abstract}

\section{ABSTRACT}

This study aims to propose a conceptual model for online learning activities in universities during the COVID-19 pandemic. This model was built by analyzing the conditions of the users, the processes and technology used by online learning during the COVID-19 pandemic. This research consists of the stages of data collection, identification of online learning activities during the COVID-19 pandemic, mapping activities on the dimensions of the model and designing a conceptual online learning model during the COVID-19 pandemic. Research data were obtained from research databases such as PubMed, ProQuest, Science Direct, Google Scholar, IEEE Xplore and Wiley Online Library. The result of the research is a conceptual model of online learning activities with a model component consisting of people (students, teachers and academic staff), process (learning/cognitive process, selfregulation in learning/student self regulation, human interaction), technology (learning management system, interaction support tools, computers/smartphones and the internet).

This is an open access article under the CC BY-SA license.

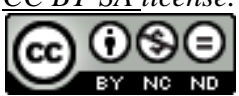

\section{Penulis Korespondensi:}

Handrie Noprisson

Fakultas Ilmu Komputer

Universitas Mercu Buana, Indonesia

Email: handrie.noprisson@mercubuana.ac.id

\section{PENDAHULUAN}

Penyebaran penyakit novel coronavirus atau COVID-19 dimulai pada akhir tahun 2019 di salah satu negara bagian di China. Kejadian ini tidak hanya berdampak pada sektor kehidupan di China, tetapi juga masyarakat di seluruh dunia. Cepatnya penyebaran virus tersebut mengakibatkan menurunnya kegiatan di bidang ekonomi dan meningkatnya penggunaan sarana di bidang kesehatan [1]-[3].

Saat wabah COVID-19 dimulai, beberapa negara langsung menerapkan regulasi jarak fisik. Sedangkan untuk wilayah dengan jumlah penderita COVID-19 yang tinggi, pemerintah telah memberlakukan aturan lockdown sehingga aktivitas seluruh sektor kehidupan terganggu [1], [4]. 
Setelah pernyataan bahwa penyebaran COVID 19 adalah 'pandemi', pemerintah melakukan berbagai pencegahan penyebaran penyakit, termasuk lockdown, pembatasan pembelajaran tatap muka, pembatasan perjalanan jarak jauh dan sebagainya [5]-[7].

Di sektor pendidikan, sebagian besar pemerintah telah menginstruksikan sekolah untuk beralih dari pembelajaran tatap muka ke pembelajaran online sepenuhnya. Semua kegiatan pembelajaran (diskusi, pelatihan, ujian, dll) dan alat penunjang pembelajaran (buku dan fasilitas lainnya) harus dalam bentuk digital agar siswa dapat diakses melalui jaringan internet [7]-[12]. Berdasarkan situasi tersebut maka penelitian tentang implementasi pembelajaran online sangat dibutuhkan.

Penelitian ini akan membahas model konseptual online learning selama pandemi COVID-19 berdasarkan studi kasus dari berbagai negara terkait sistem pembelajaran online akibat dampak wabah COVID-19. Secara spesifik pembahasan akan difokuskan pada kondisi pengguna, proses dan teknologi yang digunakan untuk mendukung keberhasilan pembelajaran online.

\section{METODE PENELITIAN}

Penelitian ini terdiri dari tahapan pengumpulan data, identifikasi aktvitas online learning selama pandemi COVID-19, pemetaan aktivitas terhadap dimensi model dan perancangan model konseptual online learning selama pandemi COVID-19. Tahapan penelitian dilakukan untuk menjawab pertanyaan penelitian seperti dapat dilihat pada Gambar 4.1 berikut ini.

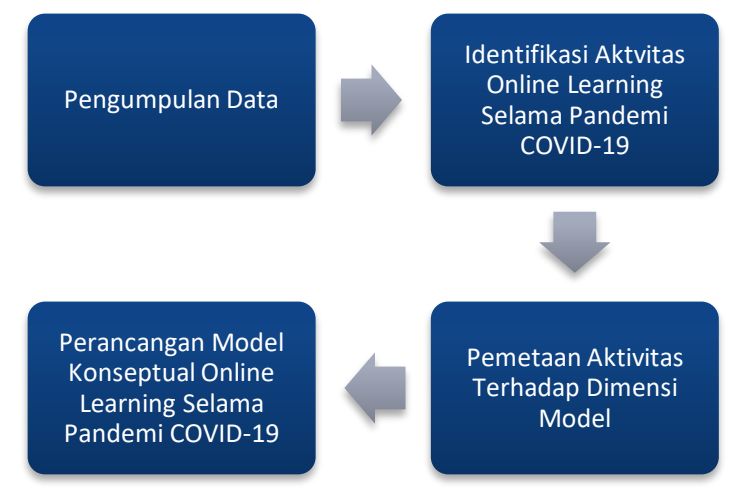

Gambar 1 Metodologi Riset

Untuk pengumpulan data, dataset akan dikumpulkan dari database penelitian seperti PubMed, ProQuest, Science Direct, Google Scholar, IEEE Xplore dan Wiley Online Library. Beberapa kata kunci digunakan dalam penelitian ini untuk mengidentifikasi makalah penelitian yang relevan, termasuk "online learning covid19", "online education covid19", "e-learning covid19", "education covid19". Semua penelitian terkait pelaksanaan pembelajaran online selama wabah COVID-19 memenuhi persyaratan untuk ditinjau dengan kriteria (i) tanggal publikasi antara 2019 dan 2020, (ii) ditulis dalam bahasa Inggris, (iii) dipublikasikan di jurnal internasional atau proceeding bereputasi, dan (v) menjelaskan aspek manusia atau proses atau teknologi yang terkait dengan pembelajaran online selama pandemi COVID-19. Hasil pengumpulan data digunakan untuk identifikasi aktivitas dan pemetaan aktivitas terhadap dimensi model online learning selama pandemi COVID-19. Untuk menyelesaikan tahap penelitian digunakan beberapa pertanyaan penelitian sebagai panduan, antara lain sebagai berikut:

1. Bagaimana aktivitas online learning pada masa pandemi COVID-19 di beberapa perguruan tinggi atau universitas?

2. Bagaimana model aktivitas online learning selama wabah COVID-19 jika mengacu pada model online learning yang telah ada?

\section{HASIL DAN ANALISIS}

Dari hasil studi didapatkan 21 penelitian yang berkaitan dengan tujuan penelitian ini yang diliha berdasarkan topik, jenis, negara dan objek sebagaimana dapat dilihat pada Tabel 1.

Tabel 1 Pengumpulan Data $(\mathrm{n}=16)$

\begin{tabular}{|l|l|l|l|l|}
\hline Referensi & \multicolumn{1}{|c|}{ Topik } & \multicolumn{1}{c|}{ Jenis } & \multicolumn{1}{c|}{ Negara } & \multicolumn{1}{c|}{ Objek } \\
\hline$[13]$ & People, Process, Technology & Review & General & Universitas (Kesehatan) \\
\hline$[14]$ & People & Case Study & Jordan & Universitas \\
\hline$[15]$ & Process & Review & Philippines & Universitas \\
\hline$[7]$ & People, Process, Technology & Case Study & India & Universitas \\
\hline$[1]$ & Technology & Case Study & Italy & Universitas \\
\hline
\end{tabular}


JSAI: Journal Scientific and Applied Informatics

Vol. 4, No. 2, Juni 2021, hal. 141-146

E-ISSN: 2614-3054; P-ISSN: 2614-3062, accredited by Kemenristekdikti, Sinta 5

DOI: 10.36085

\begin{tabular}{|l|l|l|l|l|}
\hline Referensi & \multicolumn{1}{|c|}{ Topik } & \multicolumn{1}{c|}{ Jenis } & \multicolumn{1}{c|}{ Negara } & \multicolumn{1}{c|}{ Objek } \\
\hline$[6]$ & People & Review & Philippines & Universitas \\
\hline$[5]$ & People & Case Study & Spain & Universitas (Kesehatan) \\
\hline$[16]$ & People & Review & General & Universitas \\
\hline$[17]$ & Process & Review & General & Universitas (Kesehatan) \\
\hline$[18]$ & Process & Review & General & Universitas (Kesehatan) \\
\hline$[19]$ & Process & Review & General & Universitas (Kesehatan) \\
\hline$[20]$ & Process, Technology & Review & General & Universitas (Kesehatan) \\
\hline$[21]$ & Process & Review & General & Universitas (Kesehatan) \\
\hline$[22]$ & Process & Review & China & Universitas \\
\hline$[23]$ & Process & Review & Italy & Universitas (Kesehatan) \\
\hline$[24]$ & Process & Review & General & Universitas \\
\hline
\end{tabular}

Pada penelitian ini, model online learning diusulkan dengan melihat aktivitas pembelajaran di beberapa universitas atau perguruan tinggi. Model ini mengapdatasi model online learning dari [25][26] dan framework kesuksesan manajemen pengetahuan dari [27]. Komponen pada model online learning dapat menjadi poin penting yang perlu disiapkan untuk mendukung aktivitas online learning di perguruan tinggi pada masa pandemi COVID-19. Hasil dari penelitian adalah model konseptual aktivitas online learning dengan komponen model terdiri dari people (mahasiswa, pengajar dan staf akademik), process (learning/cognitive process, pengaturan diri dalam belajar/student self regulation, interaksi manusia), technology (learning management system, interaction support tools, komputer/smartphone dan internet).
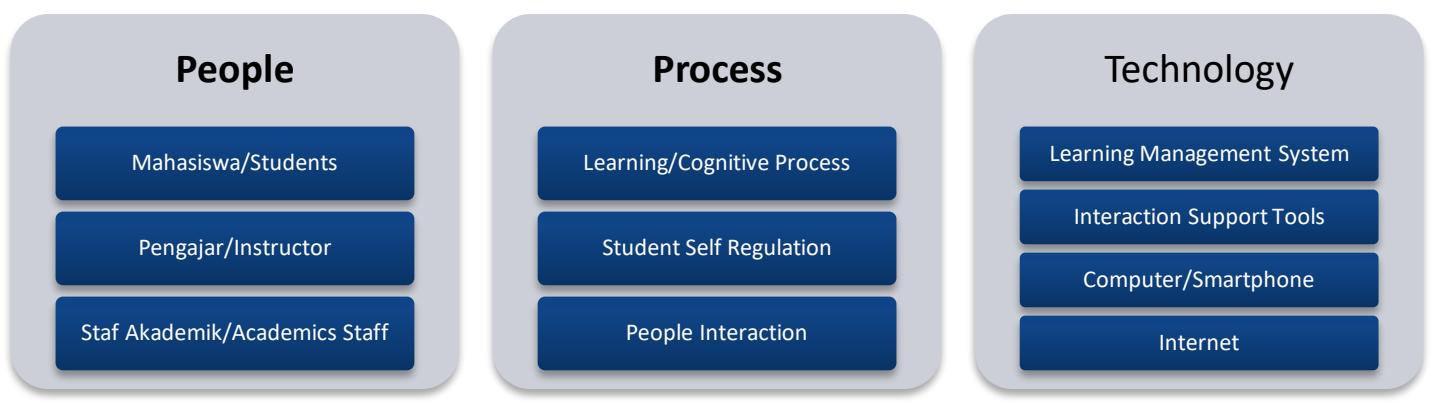

Gambar 2 Model Aktivitas Online Learning pada Masa Pandemi COVID-19

Setiap sub komponen pada model diatas memiliki aktivitas atau tugas masing-masing. Mahasiswa (students) harus memiliki usaha belajar (learning efforts) dan menyelesaikan tugas-tugas yang diberikan (task completion) oleh pengajar (instructor). Pengajar (instructor) harus dapat membuat dan menyampaikan desain pembelajaran (learning design) yang menarik dan mudah dimengerti oleh mahasiswa. Selain itu, pengajar (instructor) harus memberikan umpan balik dan penilaian (assessment) terhadap tugas-tugas yang telah diselesaikan oleh mahasiswa sebagai bagian evaluasi bagi mahasiswa. Aktivitas pembelajaran perlu untuk mendapat dukungan atau bantuan dari staf akademik (academic staff) agar dapat berjalan sesuai dengan learning design yang telah direncanakan oleh pengajar (instructor). Jika ada permasalahan teknis maka staf akademik akan berperan untuk menyelesaikan permasalah tersebut agar pembelajaran online tetap dapat berlangsung dengan baik.

Ketika proses pembelajaran berlangsung, ada tiga hal yang perlu diperhatikan antara lain learning/cognitive process (perception, attention, cognitive load, coding, retrieve/transfer dan metacognition), student self regulation (motivation dan learning strategies), dan people interaction (student-student interaction, student-instructor interaction dan academic staff-instructor interaction). semakin bagus nilai (value) yang dapat diciptakan pada setiap komponen tersebut maka akan semakin menciptakan proses pembelajaran online yang berkualitas.

Media yang mendukung proses (process) dan pengguna (people) pada pembelajaran online harus memiliki berupa teknologi yang sesuai keadaan proses dan pengguna. Namun, komponen yang harus dipenuhi agar pembelajaran online berjalan baik antara lain learning management system, interaction support tools (seperti Zoom, GoogleMeet atau WhatsApp), komputer atau smartphone dan internet. Secara detail beberapa sub komponen dari model konseptual aktivitas online learning di perguruan tinggi pada masa pandemi COVID-19 diatas dapat dijabarkan sebagai berikut: 


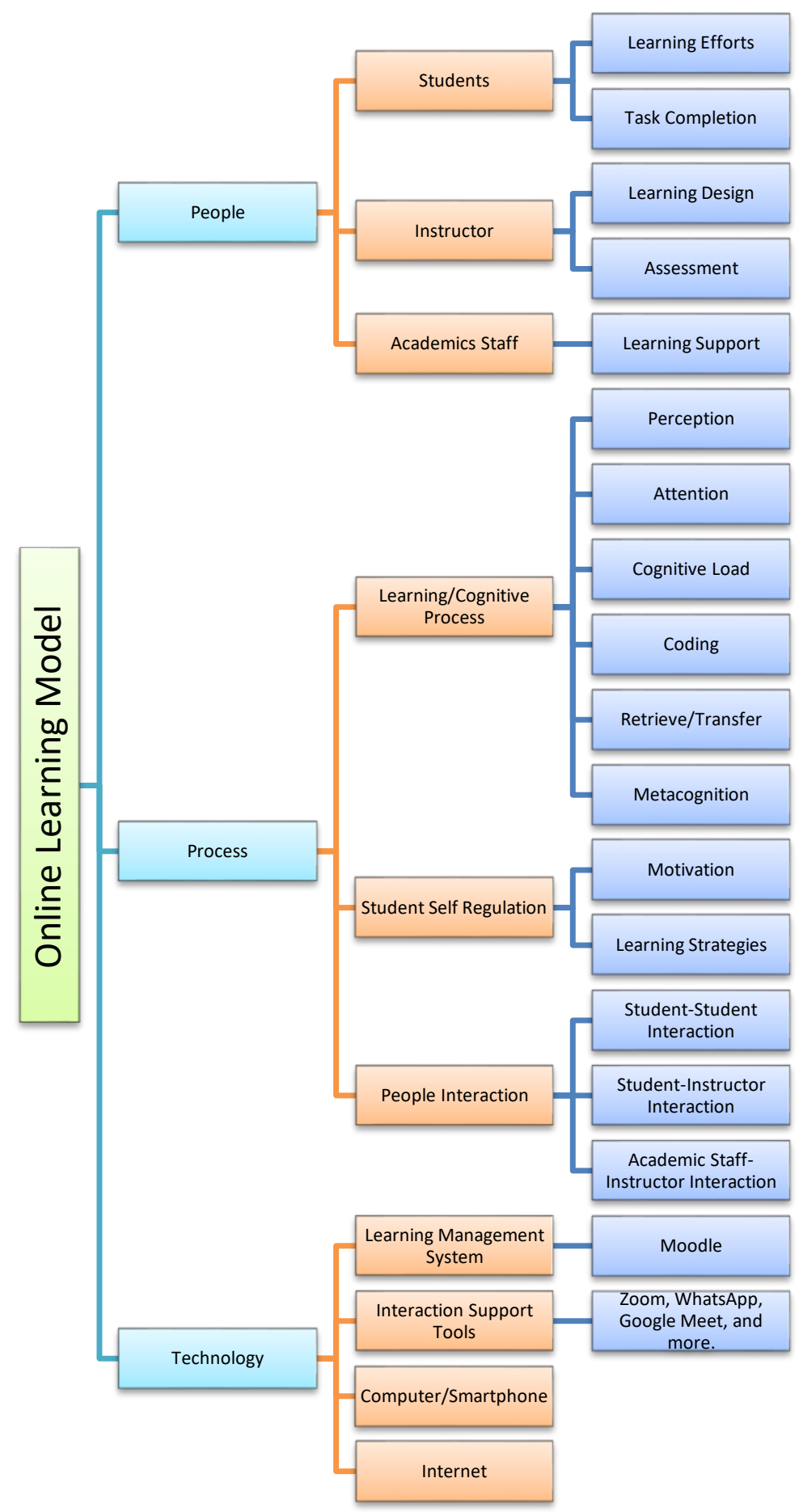

Gambar 3 Komponen Model Aktivitas Online Learning

\section{KESIMPULAN}

Penelitian ini dilakukan dengan beberapa tahapan antara pengumpulan data, identifikasi aktvitas online learning selama pandemi COVID-19, pemetaan aktivitas terhadap dimensi model dan perancangan model konseptual online learning selama pandemi COVID-19. Dari hasil akhir dari tahapan penelitian tersebut dapat disimpulkan. Model konseptual aktivitas online learning yang diusulkan memiliki komponen model yang terdiri dari people (mahasiswa, pengajar dan staf akademik), proses (learning/cognitive process, pengaturan diri dalam belajar/student self regulation, interaksi manusia), teknologi (learning management system, interaction support tools, komputer/smartphone dan internet). Semakin bagus nilai (value) yang dapat diciptakan pada setiap komponen tersebut maka akan semakin menciptakan proses pembelajaran online yang berkualitas. 


\section{UCAPAN TERIMA KASIH}

Terima kasih kepada Pusat Penelitian, Universitas Mercu Buana yang telah mendanai penelitian ini melalui skema Penelitian Internal Dosen Muda.

\section{REFERENSI}

[1] T. Favale, F. Soro, M. Trevisan, I. Drago, and M. Mellia, "Campus traffic and e-Learning during COVID-19 pandemic," Comput. Networks, vol. 176, 2020.

[2] T. H. D. Nguyen and D. C. Vu, "Food delivery service during social distancing: Proactively preventing or potentially spreading COVID-19?," Disaster Med. Public Health Prep., pp. 2019-2020, 2020.

[3] Winarsih, M. Indriastuti, and K. Fuad, "Impact of Covid-19 on Digital Transformation and Sustainability in Small and Medium Enterprises (SMEs): A Conceptual Framework," in Complex, Intelligent and Software Intensive Systems, 2020, pp. 471-476.

[4] M. Chinazzi et al., "The effect of travel restrictions on the spread of the 2019 novel coronavirus (COVID-19) outbreak," Science (80-. )., vol. 368, no. 6489, pp. 395-400, 2020.

[5] T. Gonzalez et al., "Influence of COVID-19 confinement in students performance in higher education," arXiv Prepr. arXiv2004.09545., 2020.

[6] M. Pelmin, "Readings on Coronavirus Disease (COVID-19) and the Higher Education Institution (HEIs) Emergency Preparedness in the Philippines," SSRN Electron. J., 2020.

[7] N. Kapasia et al., "Impact of lockdown on learning status of undergraduate and postgraduate students during COVID-19 pandemic in West Bengal, India," Child. Youth Serv. Rev., vol. 116, no. June, p. 105194, 2020.

[8] A. M. Connor, S. Karmokar, and C. Whittington, "From STEM to STEAM: Strategies for Enhancing Engineering \& Technology Education,” Int. J. Eng. Pedagog., vol. 5, no. 2, p. 37, 2015.

[9] R. Kandakatla, E. J. Berger, J. F. Rhoads, and J. DeBoer, "Student perspectives on the learning resources in an Active, Blended and Collaborative (ABC) pedagogical environment," Int. J. Eng. Pedagog., vol. 10, no. 2, pp. 7-31, 2020.

[10] P. Appiah-Kubi and E. Annan, "A review of a collaborative online international learning," Int. J. Eng. Pedagog., vol. 10, no. 1, pp. 109-124, 2020.

[11] H. Noprisson et al., "Influencing factors of knowledge sharing among students in Indonesia higher educational institutions," 2016 Int. Conf. Inf. Technol. Syst. Innov. ICITSI 2016 - Proc., pp. 3-8, 2017.

[12] M. Sadikin, R. Yusuf, and D. Arif Rifai, "Load balancing clustering on moodle LMS to overcome performance issue of e-learning system," Telkomnika (Telecommunication Comput. Electron. Control., vol. 17, no. 1, pp. 131-138, 2019.

[13] K. J. Dickinson and S. L. Gronseth, "Application of Universal Design for Learning (UDL) Principles to Surgical Education During the COVID-19 Pandemic," J. Surg. Educ., pp. 1-5, 2020.

[14] A. S. Haider and S. Al-Salman, "Dataset of Jordanian University Students' Psychological Health Impacted by Using E-learning Tools during COVID-19," Data Br., vol. 0, p. 106104, 2020.

[15] C. M. Toquero, "Challenges and Opportunities for Higher Education amid the COVID-19 Pandemic: The Philippine Context," Pedagog. Res., vol. 5, no. 4, p. em0063, 2020.

[16] W. Strielkowski, "COVID-19 pandemic and the digital revolution in academia and higher education," Preprints, no. April, pp. 1-6, 2020.

[17] H. Ahmed, M. Allaf, and H. Elghazaly, "COVID-19 and medical education," Lancet Infect. Dis., vol. 20, no. 7, pp. 777-778, 2020.

[18] S. Rose, "Medical Student Education in the Time of COVID-19," JAMA - J. Am. Med. Assoc., vol. 323, no. 21, pp. 2131-2132, 2020.

[19] R. C. Chick et al., "Using Technology to Maintain the Education of Residents During the COVID-19 Pandemic," J. Surg. Educ., 2020.

[20] M. Kogan, S. E. Klein, C. P. Hannon, and M. T. Nolte, "Orthopaedic Education During the COVID-19 Pandemic," J. Am. Acad. Orthop. Surg., vol. 28, no. 11, pp. e456-e464, 2020.

[21] P. Iyer, K. Aziz, and D. M. Ojcius, "Impact of COVID-19 on dental education in the United States," $J$. Dent. Educ., vol. 84, no. 6, pp. 718-722, 2020.

[22] W. Bao, "COVID -19 and online teaching in higher education: A case study of Peking University ," Hum. Behav. Emerg. Technol., vol. 2, no. 2, pp. 113-115, 2020.

[23] G. Gallo and M. Trompetto, "The effects of COVID-19 on academic activities and surgical education in Italy," J. Investig. Surg., pp. 1-2, 2020.

[24] J. Sandars et al., "Twelve tips for rapidly migrating to online learning during the COVID-19 pandemic," MedEdPublish, vol. 9, no. 1, pp. 1-14, 2020.

[25] S. B. Eom and N. Ashill, "The determinants of students' perceived learning outcomes and satisfaction 
JSAI: Journal Scientific and Applied Informatics

Vol. 4, No. 2, Juni 2021, hal. 141-146

E-ISSN: 2614-3054; P-ISSN: 2614-3062, accredited by Kemenristekdikti, Sinta 5

DOI: 10.36085

in university online education: An update," Decis. Sci. J. Innov. Educ., vol. 14, no. 2, pp. 185-215, 2016.

[26] V. van de Heyde and A. Siebrits, "The ecosystem of e-learning model for higher education," $S$. Afr. J. Sci., vol. 115, no. 5-6, pp. 1-6, 2019.

[27] C. Gorelick and B. Tantawy-Monsou, "For performance through learning, knowledge management is the critical practice," Learn. Organ., 2005. 